\title{
Meeting the Practice Challenges of COVID-19: MSW Students' Perceptions of E-Therapy and the Therapeutic Alliance
}

\author{
Melissa J. Earle ${ }^{1}$ (D) Paul P. Freddolino ${ }^{2}$ (D) \\ Accepted: 15 February 2021 / Published online: 3 March 2021 \\ (c) The Author(s), under exclusive licence to Springer Science+Business Media, LLC part of Springer Nature 2021
}

\begin{abstract}
The COVID-19 pandemic prompted a radical shift in social work practice. Overnight, social work intervention models provided in-person gave way to the utilization of Information and Communication Technologies to facilitate direct practice in virtual environments (e-therapy). Social work's slow acceptance of e-therapy prior to the pandemic resulted in a lack of training for many social work practitioners and MSW student interns, who were required to make rapid transitions to using and operating in online environments. It appears likely that e-therapy will continue after the COVID-19 pandemic subsides, so integrating education about effective e-therapy techniques into social work curricula seems like a logical next step. A social worker's ability to establish the therapeutic alliance, which is at the heart of all helping relationships, will be central to this curricula. Understanding social work students' perceptions of e-therapy and the therapeutic alliance can help shape the development of this new curriculum. Using internal student email, students at two Research I universities were invited to participate in a fully online anonymous survey dealing with attitudes towards e-therapy and the therapeutic alliance. Surveys were conducted in 2018 and April-May 2020. Survey questions were based on the only prior comprehensive study of student attitudes towards e-therapy (Finn in J Soc Work Educ 38(3), 403-419. https://doi.org/10.1080/10437797.2002.10779107, 2002). Study results indicate that students have e-therapy experience, believe that a practitioner can build a good therapeutic alliance, and think that some form of e-therapy will continue after the pandemic. These results confirm that further exploration about the inclusion of e-therapy education and its efficacy in social work curricula requires urgent attention.
\end{abstract}

Keywords E-therapy $\cdot$ Information and Communication Technologies (ICTs) $\cdot$ Therapeutic alliance $\cdot$ Social work practice $\cdot$ COVID-19

A recent report of the implementation of Information and Communication Technologies (ICTs) in the helping professions (Latifi and Doarn 2020) suggests that the COVID-19 pandemic brought immediate and possibly lasting changes to the provision of social work services. To continue to deliver social work services in a safe manner during the pandemic, social service providers and agencies had to transition immediately from seeing clients in person to virtual environments utilizing tools such as email, video conferencing and text

Melissa J. Earle

Melissa.earle.1@stonybrook.edu

Paul P. Freddolino

freddoli@msu.edu

1 School of Social Welfare, Stony Brook University, Stony Brook, NY, USA

2 School of Social Work, Michigan State University, East Lansing, MI, USA messaging as an alternative to face to face contact. Without widespread recognition and integration of professional guidelines such as the Standards for Technology in Social Work Practice (NASW, ASWB, CSWE, \& CSWA 2017a), many social workers were left without a blueprint for how to use ICTs to engage clients and provide direct practice in virtual settings ("e-therapy"). Given social work's historic ambivalence about the use of these Information and Communication Technologies (e.g. Mattison 2012; Mishna et al. 2012; Reamer 2014), social workers who were used to seeing clients face-to-face had to adjust quickly to meet COVID-19 guidelines for safe clinical practice. This education gap became apparent in the wake of COVID-19, as field education staff at the participating institutions reported that social work students cited having little direction about the use of e-therapy and developing a therapeutic alliance prior to the pandemic. 
The goal of this study of social work students' perceptions of e-therapy and the ability to form a virtual therapeutic alliance is to update the social work literature about students' views on e-therapy to support its broader inclusion in social work practice curricula. The first survey of MSW students was initiated in 2018. In spite of the steady rise in the utilization of ICTs to provide tele-behavioral health services at that time (Langarizadeh et al. 2017), barriers to the universal inclusion of education about ICTs in social work education persisted (Diaconu et al. 2019). The study was repeated in 2020, during the COVID-19 pandemic, to see if social work students' transition to virtual practice changed their perceptions of e-therapy and their ability to develop a therapeutic alliance with clients. The results of the second survey of students' perceptions of and ability to form therapeutic alliances via e-therapy were the most positive to date. The study's results viewed against the backdrop of the projections of e-therapy continuing post-pandemic (Thomas et al. 2020) and the extent of technology's influence in social work students' private and educational lives (López Peláez et al. 2017), suggest that new MSW graduates will continue to utilize ICTs in their professional social work practice. These trends offer an opportunity for social work education to consider the addition of how to establish a therapeutic alliance via ICTs to their curricula.

\section{Literature Review}

\section{Therapeutic Alliance}

The central importance of the quality of relationship between a social worker and client has been seen as a cornerstone of direct practice dating back to the early 1900s (Doran 2014). This alliance refers to the quality and strength of the collaborative relationship that involves a sense of positive regard and partnership between social worker and client in which each participant is actively committed to their specific and appropriate responsibilities in the helping relationship while believing that the other is likewise engaged in the process (Horvath and Bedi 2002). The relationship between the client and the social worker has been well researched with outcomes suggesting that the quality of this alliance is the key factor influencing change for a client, irrespective of therapeutic techniques and theoretical approaches utilized (Norcross 2002; Norcross and Wampold 2018). The therapeutic alliance or working relationship consists of three interlocking elements: a real relationship (interpersonal regard or connection); the working alliance (collaborative agreement on the goals and tasks for change); and a transference configuration for both practitioner and client (Gelso
2013). While all three of these components inform the outcome of their work together, Gelso (2013) contends that it is the interchange of the real relationship and working alliance that determines the impact and experience of change for the client.

The rise in the use of Information and Communication Technologies to provide e-therapy has resulted in a reexamination of the therapeutic alliance. A number of studies reported that therapeutic alliances established via e-therapy were equivalent to the ones formed face-to-face (Sucala et al. 2012; Kingsley and Henning 2015; Richards et al. 2016). A recent metanalysis of e-therapy literature reconfirmed the equivalency of therapeutic alliances formed via e-therapy to face-to-face modalities irrespective of targeted symptoms, frequency of therapist contact, or choice of ICT. Positive e-therapy therapeutic alliances were significantly associated with positive treatment outcomes. Building on the acceptance of the ability to form virtual therapeutic alliances, calls to pay specific attention to the selection and utilization of ICTs in e-therapy establishing this relationship have emerged (Kaiser et al. 2021).

Prior to the pandemic, studies of social work practitioners reported a mix of responses to e-therapy and the ability to form a therapeutic alliance. While a number of social work studies supported e-therapy as a viable form of social work practice (e.g. Mishna et al. 2012, 2013a, b; Lopez 2014; Cwikel and Friedmann 2019), these results were overshadowed by apprehension over e-therapy's implementation (Fitch 2015). Concerns ranged from the quality of virtual helping relationships, to the depersonalization of the therapeutic relationship, to misunderstanding non-verbal communication that may be lost in translation via ICTs (Csiernik et al. 2006; Menon and Rubin 2011; Loue 2016). Fears that the technology itself and not the practitioner would inform the engagement and process of the therapeutic alliance (e.g. Essig 2018) have joined these concerns about e-therapy.

A 2013 survey of practitioners from a variety of disciplines addressed concerns about ICTs by suggesting that a lack of information and education about e-therapy and creating virtual therapeutic alliances may underpin social workers' lack of confidence in undertaking this work (Sucala et al. 2013). Writing in the midst of the pandemic, Blumenthal (2020) acknowledged the efficacy of ICTs, but cautioned that any form of virtual care (including e-therapy) is more effective when virtual relationships with clients are developed based on longstanding principles of how to form a traditional therapeutic alliance (e.g. Norcross 2002). Education about forming therapeutic alliances via e-therapy based on traditional principles and standards could support practitioners who are transitioning to the use of ICTs as well as address the concerns expressed in the literature. 


\section{E-Therapy}

Utilizing Internet and Communication Technologies (ICTs) such as the telephone, email, video conferencing and text messaging to provide virtual professional counseling, care management, psychoeducation, or psychotherapy is known by many names. Tele-health, Tele-behavioral health, Tele-mental health, e-therapy, and Cyber Counseling are a few of the terms frequently used to describe virtual practice (Finn 2002; Langarizadeh et al. 2017; Mishna et al. 2014). Recently, the concepts of Tele-social work, Digital Social Work, and E-social work have been used to describe virtual social work practice in the literature (Goldkind et al. 2019; Hymans et al. 2020a; López Peláez and Marcuello-Servós 2018).

E-therapy was the term used for this study to define the use of technology in virtual practice due to its wide appearance in the literature. In a study of MSW students' perceptions of virtual practice, Finn (2002) noted that "e-therapy most commonly involves the exchange of one or more asynchronous email messages between a practitioner and a client. In addition, some online practitioners offer "chat," in which messages are exchanged in real-time, or two-way video conferencing, in which video images are available at the same time email messages are exchanged" (p. 404). As technology improved and its use expanded, so did the definition of e-therapy:

E-therapy is the use of electronic media and information technologies to provide services for participants in different locations. It is used by skilled and knowledgeable professionals (e.g., counselors, therapists) to address a variety of individual, familial, and social issues. E-therapy can include a range of services, including screening, assessment, primary treatment, and after care (Center for Substance Abuse Treatment 2009, p. 3).

E-therapy can stand as a sole treatment modality, or in combination with other treatment modalities and interventions. It can be provided through synchronous, "real time" delivery models such as video conferencing or through asynchronous formats such as email (Substance Abuse \& Mental Health Services Administration 2015). Recent studies suggest that there is increase in perceived efficacy and client satisfaction of e-therapy when it is delivered through synchronous platforms (Richards et al. 2016).

The strengths and limitations of e-therapy are well documented. One of the central benefits of e-therapy is its ability to reach people who traditionally would not seek services because of barriers related to social isolation, shame, guilt, stigma, financial resources, time constraints, geographic distance, care-giving responsibilities, lack of transportation, and physical or psychological disabilities
(Center for Substance Abuse Treatment 2009; Finn 2002). While research reports of the benefits of e-therapy's use during the COVID-19 may still be under review, there are indicators that its availability to provide and maintain safe service delivery has been invaluable (Nouri et al. 2020).

Commonly cited limitations of e-therapy include consensus over a unified definition or terminology about virtual practice; a lack of empirically validated models of service delivery; threats to privacy, security, and confidentiality; difficulty in providing intervention in emergency situations; technical difficulties inherent in electronic communication; and lack of access or connectivity for many clients who are technologically under resourced or not able to use the technologies available due to economic constraints, location or levels of health and technology literacy (Center for Substance Abuse Treatment 2009; Finn 2002).

\section{Social Work Education and E-Therapy}

The National Association of Social Workers' Code of Ethics emphasizes the need for social work practitioners and students to critically evaluate and stay abreast of emerging knowledge relevant to social work (NASW 2017a, b). With the increased affordability and accessibility of technology and to support the emergence of e-therapy, the Association of Social Work Boards, the Clinical Social Work Association, the Council on Social Work Education and the National Association of Social Workers has published technology standards that are aligned with the Code of Ethics to guide social workers in the use of e-therapy (ASWB, CSWA, CSWE, NASW 2017a). A recent report from the Council on Social Work Education's Futures Task Force (2015) specifically called for the inclusion of ICTs to improve social work practice at all levels as part of furthering the profession's overall mission. Despite this shift and recommendation for the inclusion of ICTs to facilitate e-therapy it is generally absent from classic generalist social work practice texts (e.g. Kirst-Ashman and Hull 2012; Shulman 2016).

Only a few studies exist which have considered social work students' perceptions of or their receiving education about providing e-therapy (Mishna et al. 2013a, b). In contrast, other helping professions such as nursing, medicine, and physical therapy included mandatory training in the use of ICTs for virtual direct client care prior to the pandemic (Guise and Wiig 2017; Skiba 2015). In some educational programs, health care students learn how to use ICTs within an interprofessional model (Begley et al. 2019).

Finn's (2002) survey of MSW students' perceptions of the efficacy of internet therapy stands as one of the most comprehensive studies of social work students and e-therapy. Results of Finn's study revealed that students' experience with e-therapy varied, they were generally consistent in their belief that e-therapy could be effective. They also 
indicated a positive attitude towards e-therapy compared to traditional practice. Given the date of Finn's study and the rise of e-therapy as part of students' contemporary direct practice environments, revisiting current students' perceptions of e-therapy and their interest in relevant content in their education and training seemed timely given the impact of the pandemic on the delivery of social work services.

\section{Methods}

\section{Study Design and Student Respondents}

This study utilizes data from cross-sectional surveys of MSW students in two accredited MSW programs at two different points in time. Using internal student email lists, invitations to complete an anonymous self-administered online survey were sent to MSW students at two large Research I public universities in the Midwest and on the East Coast of the United States. Both programs are accredited by CSWE. The survey was distributed twice, in 2018 and again in April-May 2020. It is highly unlikely that any MSW students completed the survey in both years. The second administration of the survey came during the period when both universities had migrated to fully online instruction due to the coronavirus pandemic. In addition, the service delivery systems of many health and social care agencies where students had field placements were severely impacted, with some forced to stop delivering services while others converting to e-therapy approaches such as telephone, text, and video chat service delivery. These conditions led to the addition of three specific COVID-19 questions in the 2020 survey version, while all of the original 2018 questions were retained.

\section{The Survey Instrument}

To facilitate comparisons with the results of the earlier 2002 study, the survey instrument utilized Finn's questionnaire as a base, including its definition of e-therapy. Background variables consisted of age, part-time or full-time status, and whether the students were in the Advanced Standing or Regular MSW programs. Other independent variables included a measure of current technology use and an e-therapy experience scale, both modified from Finn. Parts of two scales were retained intentionally to replicate elements of Finn's (2002) survey. A new scale was developed to examine student interest in learning about the use of technology tools in a wide range of populations and areas of practice. Three open-ended questions inquired about student attitudes toward various aspects of e-therapy.

For the 2020 version of the survey, three questions about the use of e-therapy during the coronavirus pandemic were inserted in the middle of the instrument. The first addressed any increased use of ICTs in their work or field placement since the pandemic emerged. The second contained three Likert items asking about the use of e-therapy, similar to the e-therapy attitude scale items. The final addition was a broad open-ended item asking "What do you think of e-therapy's use and effectiveness in the wake of the COVID crisis?

Current technology use scale (Table 1) consisted of six items reflecting frequency of students' use of different technologies in their own lives. The items covered an expanded set of ICTs from Finn's (2002) study to reflect the technologies currently known to be in use by students on most campuses, like social media and text messaging. Respondents were asked to indicate their response for each item using the answer that came closest to their use from the scale: $1=$ Never; $2=$ Once a month or less; $3=2-3$ times per month; $4=$ At least once per week; $5=$ Daily or almost daily. Scores were summed to create a range from 6 to 30, where high scores indicated greater use of technology.

Revised E-therapy experience scale (Table 2) consisted of the five "yes/no" items utilized by Finn such as "Do you know colleagues who provide e-therapy?" plus an additional item that reflected the reality of the contemporary social work job market, "Would you work for an e-therapy company upon graduation and licensure?" The scale has fair internal consistency with Cronbach Alpha $=.69$ in the 2018 survey and .62 in 2020.

Revised E-therapy attitude scale (Table 3) consisted of five attitude items from Finn's original 16-item scale. They were
Table 1 Current technology use scale

\begin{tabular}{|c|c|c|c|c|c|c|}
\hline \multirow{2}{*}{$\begin{array}{l}\text { How often do you use each of the fol- } \\
\text { lowing in your own life? }\end{array}$} & \multicolumn{3}{|l|}{2018} & \multicolumn{3}{|l|}{2020} \\
\hline & Mean & S.D. & $\mathrm{N}$ & Mean & S.D. & $\mathrm{N}$ \\
\hline Video chat & 2.80 & 1.19 & 143 & 3.88 & 1.11 & 185 \\
\hline A health app on your smartphone & 2.54 & 1.47 & 143 & 2.87 & 1.61 & 183 \\
\hline Text messaging & 4.96 & 0.35 & 143 & 4.94 & 0.38 & 185 \\
\hline Email (send or receive) & 4.92 & 0.27 & 142 & 4.87 & 0.38 & 184 \\
\hline Social media & 4.66 & 0.95 & 143 & 4.64 & 1.01 & 184 \\
\hline Health-related devices & 2.76 & 1.79 & 143 & 3.05 & 1.83 & 185 \\
\hline Total technology score & 22.6 & 3.68 & 141 & 24.21 & 3.91 & 182 \\
\hline
\end{tabular}


Table 2 E-therapy experience scale

\begin{tabular}{|c|c|c|c|c|c|c|}
\hline \multirow[t]{2}{*}{ Students responding "Yes" to statements about e-therapy experience } & \multicolumn{2}{|c|}{$\begin{array}{l}\text { Finn (2002) } \\
(\mathrm{N}=378)\end{array}$} & \multicolumn{2}{|c|}{$\begin{array}{l}2018 \\
(N=143)\end{array}$} & \multicolumn{2}{|c|}{$\begin{array}{l}2020 \\
(\mathrm{~N}=181)\end{array}$} \\
\hline & $\mathrm{N}$ & $\%$ & $\mathrm{~N}$ & $\%$ & $\mathrm{~N}$ & $\%$ \\
\hline Do you know colleagues who provide e-therapy? & 7 & 1.9 & 24 & 16.8 & 117 & 64.6 \\
\hline Do you know clients who have participated in e-therapy? & 7 & 1.9 & 19 & 13.3 & 114 & 63.0 \\
\hline Have you provided e-therapy yourself? & 0 & 0.0 & 8 & 5.8 & 43 & 23.8 \\
\hline Have you seriously considered providing e-therapy? & 17 & 4.6 & 38 & 26.6 & 103 & 56.9 \\
\hline Have you seen an e-therapy website? & 68 & 18.1 & 52 & 36.4 & 78 & 43.1 \\
\hline Would you work for an e-therapy company upon graduation and licensure? & & & 91 & 65.9 & 132 & 73.3 \\
\hline
\end{tabular}

${ }^{a}$ This question was developed for the 2018 survey

Table 3 Student scores on the revised e-therapy attitude scale

\begin{tabular}{|c|c|c|c|c|c|c|c|c|c|}
\hline \multirow[t]{2}{*}{ How much you agree or disagree with each statement? } & \multicolumn{3}{|c|}{ Finn (2002) } & \multicolumn{3}{|l|}{2018} & \multicolumn{3}{|c|}{2020} \\
\hline & $\mathrm{N}$ & Mean & SD & $\mathrm{N}$ & Mean & $\mathrm{SD}$ & $\mathrm{N}$ & Mean & $\mathrm{SD}$ \\
\hline E-therapy is as effective as in-person counseling & 378 & 1.81 & 0.76 & 142 & 2.87 & .90 & 174 & 3.04 & 1.02 \\
\hline An online support group is as effective as an in-person support group & 378 & 2.36 & 0.96 & 141 & 3.07 & .93 & 174 & 3.01 & 1.07 \\
\hline Some clients would do better with e-therapy than with in-person counseling & 378 & 3.12 & 0.98 & 142 & 3.78 & .76 & 174 & 3.84 & .90 \\
\hline An effective in-person counselor would also be an effective e-therapist & 378 & 2.52 & 0.90 & 142 & 3.13 & 1.00 & 174 & 3.29 & 1.06 \\
\hline A good therapeutic relationship can be established through e-therapy ${ }^{a}$ & 378 & 2.72 & 1.02 & 142 & 3.56 & .84 & 174 & 3.74 & .91 \\
\hline Total attitude score ${ }^{\mathrm{b}}$ & - & - & - & 141 & 16.4 & 3.19 & 174 & 16.9 & 3.60 \\
\hline
\end{tabular}

aThe equivalent item in Finn's survey did not include the word 'good' describing the therapeutic relationship

${ }^{\mathrm{b}}$ Finn reported aggregate data only so individual total scores could not be calculated

selected on the basis of perceived interest to contemporary students as well as to reflect a broad range of attitudes (i.e., high standard deviation) in Finn's data. For example, item 1 stated "E-therapy is as effective as in-person counseling." Respondents' level of agreement or disagreement was rated $1=$ Strongly Disagree $(\mathrm{SD}) ; 2=$ Disagree $(\mathrm{D}) ; 3=$ Neither Disagree or Agree (N); $4=$ Agree (A); $5=$ Strongly Agree (SA). Scores were summed to create a range from 5 to 25 , where high scores reflected more positive attitudes toward e-therapy. The scale showed good reliability with a Cronbach Alpha measure of internal consistency at 0.77 in both the 2018 and 2020 surveys.

\section{Analysis Plan}

The 2018 and 2020 data were analyzed using IBM SPSS Statistics Version 26. T-test comparisons of means were computed wherever appropriate, and the influential effects of all independent variables were examined in bivariate analyses. The published results of Finn's (2002) study were available, and these were included in the results whenever possible to explore any changes in the patterns of responses from that earlier period. Data from the questions related to the use of e-therapy in response to the COVID-19 pandemic that were added for the 2020 survey were of particular interest.

\section{Results}

\section{Characteristics of the Students}

Response rates on the survey were $15.3 \%(\mathrm{~N}=143)$ in 2018 , and $17.3 \%(\mathrm{~N}=185)$ in 2020 , but it must be noted that these rates are based on the total number of student subscribers to the email lists, not the number that made it through spam filters or the number of emails opened and read by students with surveys subsequently not completed. Student respondents in the 2018 and 2020 surveys were quite similar. In terms of age, the 2018 mean was $32.3(\mathrm{SD}=10.1)$ while in 2020 it was $32.9(\mathrm{SD}=10.2)$. 
Finn (2002) reported only the median age of 27 . The 2018 respondents had a median age of 28 , while in 2020 it was 29.

In the 2020 sample, most respondents $(63.6 \%, n=117)$ were full-time students, compared to $52.4 \%(\mathrm{n}=75)$ in the 2018 sample. In terms of program, in the 2020 sample $75.7 \%(n=140)$ were in the traditional MSW option, with the balance in the Advanced Standing option. This compares with $83.9 \%$ in the traditional MSW option in the 2018 sample.

In terms of technology use, Finn described his sample as "generally experienced computer users," but his technology use questions asked only about how long students had used the internet and how frequently they used it. The Current Technology Use (CTU) scale developed for the 2018 and 2020 surveys included frequency of use of video chat, smartphone health applications, text messaging, email, social media, and health-related devices (such as Fitbits). The scale ranged from (1) Never to (5) Daily. Table 1 shows results for 2018 and 2020.

The results show an overall increase in technology use from 2018 to $2020, t(321)=-3.67, p<.001$. The most notable increase was in video chat, and smaller increases in smartphone health applications and in health-related devices.

Finn (2002) reported that his sample of students had very little experience with e-therapy. None reported every having provided e-therapy themselves, and only $4.6 \%$ indicated they had seriously considered providing e-therapy (see Table 2 ). By $2018,5.8 \%(\mathrm{~N}=8)$ reported having provided e-therapy, and $26.6 \%(\mathrm{~N}=38)$ seriously considered providing e-therapy (see Table 2). By the 2020 survey the portion of respondents who had provided e-therapy quadrupled to $23.8 \%(\mathrm{~N}=43)$, and $56.9 \%$, double the 2018 percentage, seriously considered providing e-therapy. There was a significant difference between 2018 and 2020, $t(320)=8.99, p<.001$.

For the 2018 survey a new question was added to reflect the reality in social work practice that a number of companies were providing e-therapy services (Goodheart 2017). Even as early as the 2018 survey, despite the fact that only $5.8 \%$ of respondents had experience providing e-therapy, $65.9 \%(\mathrm{~N}=91)$ reported that they would "work for an e-therapy company upon graduation and licensure." By the 2020 survey this portion had grown to nearly three-quarters of the respondents $(73.3 \%, \mathrm{~N}=132)$.

\section{Revised E-Therapy Attitudes Scale}

In both 2018 and 2020 students were asked about their agreement with a set of five attitudes selected from Finn's original scale, using the following choices: $1=$ Strongly Disagree (SD); $2=$ Disagree (D); $3=$ Neither Disagree or Agree (N); $4=$ Agree (A); 5 = Strongly Agree (SA). Results on these five items from Finn (2002) and from the 2018 and 2020 surveys are presented in Table 3. Student attitudes on all five items were much more positive toward various elements of e-therapy in 2018 than in 2002, but without Finn's individual data $t$-tests could not be computed. They were more accepting of e-therapy's equivalency to in-person therapy (mean 2.87 versus 1.81 ), believed that e-therapy is a better option for some clients (mean 3.78 versus 3.12), and were more accepting of the notion that a good therapeutic relationship can be established through e-therapy (mean 3.56 versus 2.72). Although there was no statistically significant difference in means, the 2020 results showed even greater acceptance compared to 2018 on four of the five items, with even the attitude toward effectiveness of online support groups still considerably more accepting than in 2002.

\section{E-Therapy and the COVID-19 Pandemic}

When asked in the 2020 survey if their use of ICTs for social work practice (professionally and/or in field internship) had increased since the COVID-19 pandemic emerged, an overwhelming $81.9 \%$ ( $\mathrm{N}=136$ of 166 respondents) reported that it had. Among the 135 students who reported which technologies they had started using, 122 (90.4\%) reported starting to use video calls; 51 (37.8\%) started text messaging; 68 (50.4\%) initiated email use for therapy; and 76 (56.3\%) began mobile phone use in their practice.

The 2020 survey included three questions addressing student attitudes toward e-therapy in the context of the pandemic; results are reported in Table 4. Responses ranged from $1=$ Strongly disagree to $5=$ Strongly agree. The results are comparable to the e-therapy attitude items asked in the general practice context reported in Table 3 above. Of most interest is their opinion that a good therapeutic relationship can be established through e-therapy $($ Mean $=3.78$, $\mathrm{SD}=.869$ ).

The results of the 2020 survey's open ended question about the use and effectiveness of e-therapy during the
Table 4 Student responses on three pandemic e-therapy attitude items in the 2020 survey

\begin{tabular}{llll}
\hline How much do you agree or disagree with each statement? & $\mathrm{N}$ & Mean & SD \\
\hline Video based E-therapy is as effective as in-person counseling & 169 & 3.08 & 1.006 \\
$\begin{array}{l}\text { Some clients would do better with video based e-therapy than with in- } \\
\text { person counseling }\end{array}$ & 169 & 3.78 & .885 \\
\begin{tabular}{l} 
A good therapeutic relationship can be established through e-therapy \\
\hline
\end{tabular} & 169 & 3.78 & .869 \\
\hline
\end{tabular}


COVID-19 crisis yielded a mix of students' perceptions and acceptance of it. These responses aligned with e-therapy's benefits and limitations previously cited in the literature. Students were almost unanimous is their recognition of the value of e-therapy as the safest way to maintain their relationships with their clients during the pandemic. Students' focus on client centered care and the therapeutic alliance figure prominently in their commentary ("I think it's very useful and of benefit to many clients in need. COVID-19 is taking and took a toll on many people's mental health. Being able to provide e-therapy during these times is a blessing to many. It can potentially save lives"). Students who did report ambivalence in their own perceptions of the efficacy of e-therapy also acknowledged its potential to meet client needs ("I'm undecided about effectiveness but clients prefer the idea of it"). Student reflections regarding e-therapy's efficacy during the COVID crisis subsided ranged from a begrudging ("it's better than nothing") to full acceptance of its use ("the whole thing is a big opportunity"; "it's awesome!"). Students also noted e-therapy's ability to increase access to those who would not otherwise be served in faceto-face environments ("it expands our service to clients who we would never be able to geographically reach before"). They also expressed concern about those clients with limited internet connectivity ("it's good to reach more people but what about clients who do not have a phone or good internet?").

\section{Bivariate Results}

Respondents to the 2020 survey showed no differences in Current Technology Use, E-therapy Experience, the Revised E-therapy Attitude Scale, or in the three-item 'pandemic attitude scale' between full and part-time students, or between Advanced Standing and Regular MSW students. There is a small correlation between age and E-therapy Experience $(r=0.21, p=.006)$, suggesting that younger students were more likely to have provided e-therapy themselves or be interested in working for an e-therapy company, but age was not correlated with e-therapy attitudes in general or with the three 'COVID-19' items reported in Table 4. In the 2018 survey there were no correlations between age and any of the scales, and no differences between Advanced Standing and regular MSW students. The only difference between fulltime and part-time students in 2018 was in regard to attitudes toward e-therapy, where part-time students were more positive than full-time students in the Revised E-therapy Attitude Scale $(t=-1.97, d f=139)$.

\section{Limitations}

Perhaps the most significant limitation in this study is one shared with much of the research in the arena of technologysupported practice. In both Finn's original 2002 study and the 2018 and 2020 surveys the definition of e-therapy was intentionally left very broad, to capture a set of technologysupported practices that have only recently been emerging in use, and even with the mandated transitions in response to the COVID-19 pandemic remain quite varied with multiple definitions depending on the specific tool used and provider preferences. Tightening the definition would have meant excluding practices that fall under the broad umbrella of e-therapy or e-social work.

The other main area of limitations is in the sample of students in the 2018 and 2020 surveys. Both samples consisted of students from only two campuses with regional rather than national student bodies and thus somewhat narrow demographic characteristics. Both had relatively low response rates, reflecting both student distractions toward the end of the academic year and the increasing number of survey requests received by students, although as noted above these reported response rates cannot factor in emails that were redirected by spam filters or otherwise never seen by students. In any case these low rates mean that the conclusions can only be considered suggestive rather than definitive.

While survey questions were modified to reflect the changed environment of both technology and social work practice almost 20 years later, the number of items in several of Finn's original scales were reduced. While the intent was to constrain the total length of the survey, the inevitable result was a narrowing of the scope of the issues covered.

Finally, in terms of the central theme of "relationship", it is important to note that the term "therapeutic relationship" was not defined in Finn's initial study, and it remained undefined in the two recent surveys other than to add the qualifier "good therapeutic relationship". Because of the importance of the therapeutic relationship in social work this is an area that needs to be addressed in future research related to the increased use of technology tools in practice.

\section{Discussion}

E-therapy's acceptance has risen steadily over the past two decades with its use escalating beyond anyone's expectation in the wake of the COVID-19 pandemic and the restrictions 
that have been put in place across the world. The use of ICTs to provide e-therapy and other telecare has been recognized as a viable way to provide health and behavioral health services both now and in the future (Latifi and Doarn 2020). Medicaid and Medicare policy have supported this shift in delivery by including a greater number of tele-health and tele-behavioral health services (Centers for Medicare $\&$ Medicaid Services 2020). Health care provided via ICTs during the pandemic has highlighted health disparities for marginalized and vulnerable people, that could be affordably and easily addressed through the use of tele services but only if they have access to ICT (Nouri et al. 2020). Social workers have identified e-therapy as a necessary response to the COVID-19 pandemic (Hymans et al. 2020b). Despite the growing support for e-therapy, concerns about a practitioner's ability to develop meaningful therapeutic alliances within virtual environments linger (Blumenthal 2020).

Representing the next generation of social work practitioners, the students who participated in this study have provided a glimpse into the future use of ICTs in social work practice. Their responses in the 2020 survey indicate that they are technology savvy and that overall, they have accepted the use of e-therapy. Students indicated that they expect to continue to use ICTs in social work practice postpandemic, and that they will actively consider e-therapy employment opportunities upon graduation.

The therapeutic alliance remains at the heart of direct practice and students reported they were confident in their abilities to develop these relationships in virtual environments. Given the rapid technological growth and acceptance of ICTs in health and behavioral health care, it is likely that future social work students entering MSW programs will be as equally comfortable with technology and will expect to be taught about how it can used effectively and ethically social work practice.

\section{Implications for Social Work Education}

Information and Communication Technologies (ICTs) are constantly evolving, changing the way we live and work and this has been accelerated due to COVID-19. Understanding the importance of meeting the demands of an ever changing field, social work's governing bodies' guidelines and codes require social workers to incorporate current trends and interventions in the field in their practice (Council on Social Work Education 2015; NASW 2017a, b). The Council on Social Work Education required schools of social work to educate social work students in emerging forms of technology in its 2015 educational standards (Council on Social Work Education 2015). In 2017, NASW included social worker's ethical use of technology in its Code of Ethics
(NASW 2017a, b). While some social workers may have been prepared for the rapid shift away from in-person to virtual social work practice, caused by the COVID-19 pandemic, many social work students and educators were not.

This study confirms and supports the current social work governing principles stipulating that social workers need to understand and use technology appropriately in their practice. As a profession we need to establish how to use of e-therapies to establish viable professional relationships with clients; and importantly how to integrate these practices into social work education.

The COVID-19 pandemic has by necessity provided current social work students with a formative education in e-therapy, which is a form of direct practice that is likely to continue after the pandemic ends. One of the enduring challenges for social work education are the decisions about what forms of virtual practice are ethical and appropriate as well as reflect core values of the profession.

Social work has a foundational commitment to social justice. The COVID-19 pandemic revealed drastic health inequalities, particularly for marginalized and vulnerable populations. These disparities, including access to care, were addressed in part through the emergency implementation of e-therapy and other forms of virtual care, but they also highlighted digital inequalities in our society (Nouri et al. 2020). The 2020 survey confirmed that current social work students recognize the benefits of increased virtual access to services for their clients. At the same time, they also worried about how clients with limited resources to connect online would initiate or maintain access to care once the pandemic was over. The benefits and use of technology to serve clients has been affirmed during the pandemic. There has been increased access to care, facilitated by the changes to policy and the provision of virtual social work services. Social work students have embraced E-therapy, and are, and should be, provided with the knowledge and skills to continue to practice in both the face to face and screen to screen environments in their formative social work education.

Author Contributions All authors contributed to the study conception and design. Material preparation, data collection and analysis were performed by Dr. MJE, and Dr. PPF. The first draft of the manuscript was written by Dr. MJE and all authors commented on previous versions of the manuscript. All authors read and approved the final manuscript.

Funding Not applicable. This was an unfunded study.

Data Availability Dr. Melissa J. Earle and Dr. Paul P. Freddolino confirm that all data and materials as well as software application or custom code support their published claims and comply with field standards. 
Code Availability Not applicable.

\section{Compliance with Ethical Standards}

Conflict of interest The authors declare that they have no conflict of interest.

Ethical Approval Stony Brook University IRB approval (Exempt)Study \# 1287788-3; COHIRS\# 2018-4734-F. Michigan State University IRB approval (Exempt)—Study \# 00000651.

Consent to Participate Informed consent was obtained from all individual participants included in the study.

Consent for Publication Not applicable. All participants were anonymous.

\section{References}

Begley, K., O’Brien, K., Packard, K., Castillo, S., Haddad, A. R., Johnson, K., Coover, K., \& Pick, A. (2019). Impact of interprofessional telehealth case activities on students' perceptions of their collaborative care abilities. American Journal of Pharmaceutical Education, 83(4), 6880. https://doi.org/10.5688/ajpe6880

Blumenthal, D. (2020). Where telemedicine falls short. Harvard Business Review-Digital Articles, 2-4.

Bureau of Labor Statistics, U.S. Department of Labor, Occupational Outlook Handbook, Social Workers, on the Internet at https:// www.bls.gov/ooh/community-and-social-service/social-worke rs.htm (visited July 12, 2020).

Center for Substance Abuse Treatment. (2009). Considerations for the Provision of E-Therapy. HHS Publication. No. (SMA) 09-4450. Rockville, MD: Center for Substance Abuse Treatment, Substance Abuse and Mental Health Services Administration.

Centers for Medicare and Medicaid Services. (2020, October 14). State Medicaid \& CHIP Telehealth Toolkit Policy Considerations for States Expanding Use of Telehealth (Centers for Medicare and Medicaid Services, Author; State Medicaid \& CHIP Telehealth Toolkit). https://www.medicaid.gov/medicaid/benefits/downloads/ medicaid-chip-telehealth-toolkit-supplement1.pdf.

Council on Social Work Education. (2015, June). 2015 Educational Policy and Accreditation Standards. https://www.cswe.org/Accre ditation.aspx.

Csiernik, R., Furze, P., Dromgole, L., \& Rishchynski, G. M. (2006). Information technology and social work-The dark side or light side? Journal of Evidence-Based Social Work, 3(3-4), 9-25. https ://doi.org/10.1300/J394v03n03_02

Cwikel, J., \& Friedmann, E. (2019). E-therapy and social work practice: Benefits, barriers, and training. International Social Work, 63(6), 730-745. https://doi.org/10.1177/0020872819847747

Diaconu, M., Racovita, L. D., Carbonero Muñoz, D., \& Faubert, S. J. (2019). Social work educators' perceived barriers to teaching with technology: The impact on preparing students to work with younger clients. Social Work Education, 39(6), 785-812. https:// doi.org/10.1080/02615479.2019.1683155

Doran, J. M. (2014). The working alliance: Where have we been, where are we going? Psychotherapy Research, 26(2), 146-163. https:// doi.org/10.1080/10503307.2014.954153

Envisioning the Future of Social Work: Report of the CSWE Futures Task Force (pp. 1-22, Rep.). (n.d.).

Essig, T. (2018, June 7). Sleepwalking towards artificial intimacy: How psychotherapy is failing the future. Forbes. https://www.forbe s.com/sites/toddessig/2018/06/07/sleepwalking-towards-artificial -intimacy-how-psychotherapy-is-failing-the-future/\#f4c9b72403 73.

Finn, J. (2002). MSW student perceptions of the efficacy and ethics of internet-based therapy. Journal of Social Work Education, 38(3), 403-419. https://doi.org/10.1080/10437797.2002.10779107

Fitch, D. (2015). A conceptual framework for information technology in social work practice. Advances in Social Work, 16(1), 15-30. https://doi.org/10.18060/18291

Gelso, C. (2013). A tripartite model of the therapeutic relationship: Theory, research, and practice. Psychotherapy Research, 24(2), 117-131. https://doi.org/10.1080/10503307.2013.845920

Goldkind, L., Wolf, L., \& Freddolino, P. P. (2019). Digital social work: Tools for practice with individuals, organizations, and communities. New York, NY: Oxford University Press.

Goodheart, J. (2017, May 24). Online Therapy Shows Promise But Raises Plenty of Ethical Questions. Fast Company. https://www. fastcompany.com/40423793/online-therapy-shows-promise-butraises-plenty-of-ethical-questions.

Guise, V., \& Wiig, S. (2017). Perceptions of telecare training needs in home healthcare services: A focus group study. BMC Health Services Research, 17(1), 1-10. https://doi.org/10.1186/s1291 3-017-2098-2

Horvath, A. O., \& Bedi, R. P. (2002). The Alliance. In J. C. Norcross (Ed.), Psychotherapy relationships that work: Therapist contributions and responsiveness to patients (pp. 37-69). New York: Oxford University Press.

Hymans, D. J., Coffey, D. S., \& McClain, A. (2020a, May 15). Let's call it what it is: Telesocialwork. Social Work Responds. https ://cswe.org/News/General-News-Archives/Lets-Call-it-What-itis-Telesocialwork.

Hymans, D. J., Coffey, D. S., \& McClain, A. (2020b, October 23). How do you eat an elephant? Social Work Responds. https:// www.cswe.org/News/General-News-Archives/How-Do-YouEat-an-Elephant.

Kaiser, J., Hanschmidt, F., \& Kersting, A. (2021). The association between therapeutic alliance and outcome in internet-based psychological interventions: A meta-analysis. Computers in Human Behavior, 114, 106512. https://doi.org/10.1016/j.chb.2020.106512

Kingsley, A., \& Henning, J. (2015). Online and phone therapy: Challenges and opportunities. The Journal of Individual Psychology, 71(2), 185-194

Kirst-Ashman, K. K., \& Hull, G. H. (2012). Understanding generalist practice (6th ed.). Boston, MA: Brooks/Cole, Cengage Learning.

Langarizadeh, M., Tabatabaei, M., Tavakol, K., Naghipour, M., \& Moghbeli, F. (2017). Telemental health care, an effective alternative to conventional mental care: A systematic review. Acta Informatica Medica, 25(4), 240. https://doi.org/10.5455/ aim.2017.25.240-246

Latifi, R., \& Doarn, C. R. (2020). Perspective on COVID-19: Finally, telemedicine at center stage. Telemedicine and E-Health, 26(9), 1106-1109. https://doi.org/10.1089/tmj.2020.0132

Lopez, A. (2014). An investigation of the use of internet based resources in support of the therapeutic alliance. Clinical Social Work Journal, 43(2), 189-200. https://doi.org/10.1007/s1061 5-014-0509-y

López Peláez, A., \& Marcuello-Servós, C. (2018). E-Social work and digital society: Re-conceptualizing approaches, practices and technologies. European Journal of Social Work, 21(6), 801-803. https://doi.org/10.1080/13691457.2018.1520475

López Peláez, A., Pérez García, R., \& Aguilar-Tablada Massó, M. V. (2017). E-Social work: Building a new field of specialization in social work? European Journal of Social Work, 21(6), 804-823. https://doi.org/10.1080/13691457.2017.1399256. 
Loue, S. (2016). Ethical use of electronic media in social work practice. Revista Romaneasca Pentru Educatie Multidimensionala, VIII(2), 21-30. https://doi.org/10.18662/rrem/2016.0802.02

Mattison, M. (2012). Social work practice in the digital age: Therapeutic e-mail as a direct practice methodology. Social Work, 57(3), 249-258. https://doi.org/10.1093/SW/SWS021

Menon, G. M., \& Rubin, M. (2011). A survey of online practitioners: Implications for education and practice. Journal of Technology in Human Services, 29(2), 133-141. https://doi.org/10.1080/15228 835.2011.595262

Mishna, F., Bogo, M., Root, J., Sawyer, J.-L., \& Khoury-Kassabri, M. (2012). "It just crept in": The digital age and implications for social work practice. Clinical Social Work Journal, 40(3), 277-286. https://doi.org/10.1007/s10615-012-0383-4

Mishna, F., Bogo, M., \& Sawyer, J.-L. (2013a). Cyber counseling: Illuminating benefits and challenges. Clinical Social Work Journal, 43(2), 169-178. https://doi.org/10.1007/s10615-013-0470-1

Mishna, F., Levine, D., Bogo, M., \& Van Wert, M. (2013b). Cyber counselling: An innovative field education pilot project. Social Work Education, 32(4), 484-492. https://doi.org/10.1080/02615 479.2012.685066

Mishna, F., Bogo, M., Root, J., \& Fantus, S. (2014). Here to stay: Cyber communication as a complement in social work practice. Families in Society: The Journal of Contemporary Social Services, 95(3), 179-186. https://doi.org/10.1606/1044-3894.2014.95.23

National Association of Social Workers. (2017a). NASW, ASWB, CSWE \& CSWA Standards for technology in social work practice. Retrieved from https://www.socialworkers.org/includes/ newIncludes/homepage/PRA-BRO-33617.TechStandards_FINAL _POSTING.pdf.

National Association of Social Workers. (2017b). Code of ethics of the National Association of Social Workers. Retrieved from www. naswdc.org/pubs/code/code.asp.

Norcross, J. C. (2002). Empirically supported therapy relationships. In J. C. Norcross (Ed.), Psychotherapy relationships that work: Therapist contributions and responsiveness to patients (pp. 3-16). New York: Oxford University Press.

Norcross, J. C., \& Wampold, B. E. (2018). A new therapy for each patient: Evidence-based relationships and responsiveness. Journal of Clinical Psychology, 74(11), 1889-1906. https://doi. org/10.1002/jclp. 22678

Nouri, S., Khoong, E. C., Lyles, C. R., \& Karliner, L. (2020). Addressing equity in telemedicine for chronic disease management during the Covid-19 pandemic. New England Journal of Medicine/ Catalyst, May 4th. https://doi.org/10.1056/CAT.20.0123. https:// catalyst.nejm.org.
Reamer, F. G. (2014). Clinical social work in a digital environment: Ethical and risk-management challenges. Clinical Social Work Journal, 43(2), 120-132. https://doi.org/10.1007/s1061 5-014-0495-0

Richards, P., Simpson, S., Bastiampillai, T., Pietrabissa, G., \& Castelnuovo, G. (2016). The impact of technology on therapeutic alliance and engagement in psychotherapy: The therapist's perspective. Clinical Psychologist, 22(2), 171-181. https://doi. org/10.1111/cp.12102

Shulman, L. (2016). The skills of helping individuals, families, groups and communities (7th ed.). Boston, MA: Brooks/Cole Cengage Learning.

Skiba, D. (2015). Connected health: Preparing practitioners. Nursing Education Perspectives, 36(3), 198-201. https://doi. org/10.5480/1536-5026-36.3.198

Substance Abuse and Mental Health Services Administration. (2015). Using Technology-Based Therapeutic Tools in Behavioral Health Services. Treatment Improvement Protocol (TIP) Series 60. HHS Publication No. (SMA) 15-4924. Rockville, MD: Substance Abuse and Mental Health Services Administration.

Sucala, M., Schnur, J. B., Constantino, M. J., Miller, S. J., Brackman, E. H., \& Montgomery, G. H. (2012). The therapeutic relationship in e-therapy for mental health: A systematic review. Journal of Medical Internet Research, 14(4), e110. https://doi.org/10.2196/ jmir.2084

Sucala, M., Schnur, J., Brackman, E., Constantino, M., \& Montgomery, G. (2013). Clinicians' attitudes toward therapeutic alliance in e-therapy. The Journal of General Psychology, 140, 282-293.

Thomas, E. E., Haydon, H. M., Mehrotra, A., Caffery, L. J., Snoswell, C. L., Banbury, A., \& Smith, A. C. (2020). Building on the momentum: Sustaining telehealth beyond COVID-19. Journal of Telemedicine and Telecare, O(0), 1-8. https://doi. org/10.1177/1357633X20960638

Publisher's Note Springer Nature remains neutral with regard to jurisdictional claims in published maps and institutional affiliations.

Melissa J. Earle is an LCSW with over years of experience working with trauma, addiction, mental illness, and veterans. Dr. Earle's other area of interest is the study of best practices for integrating technology into social work practice and education. 